\title{
X-Ray Absorption Near Edge Structure and Mössbauer Spectroscopy in Study of Iron Valence States in Tissues
}

\author{
K. Dziedzic-KocureK ${ }^{a}$, A. Banaśs ${ }^{b}$, W.M. KWiateK ${ }^{b}$ \\ AND J. STANEK ${ }^{a}$ \\ ${ }^{a}$ Institute of Physics, Jagiellonian University \\ Reymonta 4, 30-059 Kraków, Poland \\ ${ }^{b}$ Institute of Nuclear Physics, Radzikowskiego 152, 31-342 Kraków, Poland \\ X-ray absorption near edge structure Fe $K$-edge spectra and ${ }^{57} \mathrm{Fe}$ \\ Mössbauer spectra of selected standard compounds were recorded at room \\ temperature. Valence and spin states of Fe in these samples known from \\ Mössbauer spectroscopy were correlated with the shapes of X-ray absorp- \\ tion near edge structure spectra in search of possible application of X-ray \\ absorption near edge structure spectroscopy as analytical tool determining \\ local electronic states of iron in tissues. As an example, the X-ray absorption \\ near edge structure spectra of healthy and cancerous tissues of prostate are \\ shown, suggesting $\mathrm{Fe}^{3+}$ in cancerous tissues.
}

PACS numbers: 61.18.Fs, 61.10.Ht

\section{Introduction}

Various metals act as catalysts in the oxidative damage of biological macromolecules, and therefore, the toxicity associated with these metals may be due, at least in part, to their ability to generate free radicals [1]. To understand the role of iron in the oxidative stress which may be an important factor in the pathogenesis of cancer, its chemical state in normal and neoplasmatic tissues of prostate was investigated [2].

The application of the Mössbauer spectroscopy for the determination of the valence and spin states of iron is obvious. However, in case of iron in tissues, even in their lyophilized forms, this method often fails due to the low concentration of the Mössbauer probe. X-ray absorption near edge structure (XANES) requires a smaller amount of iron and is not restricted to lyophilized samples but the interpretation of spectra is not straightforward. By searching for the correlation between 
the results obtained by both methods one may avoid limitations characteristic of each technique.

Due to the notation of Natoli and Benfatto XANES region can be divided into three parts [3]:

a) the pre-edge (PE) subregion that has its origin in quadrupolar (weak) and dipole-forbidden (strong) transitions from the $1 s$ core states to $3 d$ molecular orbital with some $p$ character. Thus, a shape, position, and intensity of $\mathrm{PE}$ depend on the $3 d-4 p$ hybridization, which is related to the local atomic coordination;

b) the full multiple scattering (FMS) subregion - real absorption edge with its crest ("white line") that is the most intense one, the shape and energy shift of that subregion depends mainly on the valence state of the absorbing atom;

c) the intermediate multiple scattering (IMS) subregion, not considered in this paper, which contains features describing structural properties of the compound arising from multiple-scattering contributions.

Thus, XANES spectra are influenced by both, local electronic and local crystallographic states of absorbing atoms. Unambiguous quantitative analysis of those XANES subregions may be performed by computer simulations if one of these factors is known. Evidently, structural information of iron in tissues cannot be reached out with the use of typical crystallographic methods. In this work we attempt to find some simple, phenomenological relation between the local electronic states of iron in solids and the shapes of XANES spectra, neglecting the structural details. That is why general, qualitative aspects have been considered, mainly by comparing the shape and position of the PE and FMS subregions with data obtained from the Mössbauer investigations on the same samples.

\section{Methods}

XANES experiments were carried out on the L-beam line (HASYLAB, DESY, Germany) in fluorescence mode. The white synchrotron radiation beam was monochromatized and set to $7.112 \mathrm{keV}$. Selected compounds such as: $\mathrm{Fe}(\mathrm{met}), \mathrm{Fe}_{2} \mathrm{O}_{3}, \mathrm{Fe}_{3} \mathrm{O}_{4},(\mathrm{Fe}, \mathrm{Mg})_{2} \mathrm{SiO}_{4}, \mathrm{Na}_{4}\left[\mathrm{Fe}(\mathrm{CN})_{6}\right], \mathrm{Na}_{2}\left[\mathrm{Fe}(\mathrm{CN})_{5} \mathrm{NO}\right]$, $\mathrm{Fe}\left(\mathrm{ClO}_{4}\right)_{2}, \mathrm{Fe}\left(\mathrm{NH}_{4}\right)\left(\mathrm{SO}_{4}\right)_{2},\left[\mathrm{Fe}\left(\mathrm{C}_{6} \mathrm{H}_{6} \mathrm{O}_{4}\right)_{3}\right]$ (1) (kojic acid - $\left.\left[\mathrm{Fe}(\mathrm{Hka})_{3}\right]\right)$ and $\left[\mathrm{Fe}\left(\mathrm{C}_{7} \mathrm{H}_{7} \mathrm{O}_{3}\right)_{3}\right](2)$ (ethylmaltol - $\left.\left[\mathrm{Fe}(\text { etmal })_{3}\right]\right)$ were chosen as standards for an appropriate oxidation spin state of iron. Two last compounds are organic ligands of natural origin and have an application in food, pharmaceutical, or cosmetic industries. They reveal biological activity in iron complexes. In both complexes Fe is in $3+$ (high spin state) in the disordered octahedral coordination [4]. The difference is in the hydroxy-group for (1) and ethyl-group for (2) that not directly coordinate the Fe ion.

Iron XANES spectra were collected from about $22 \mathrm{eV}$ below to $38 \mathrm{eV}$ above the absorption edge for metallic iron so called $\mathrm{Fe}(0)$ (the absorption edge is at 
$7112 \mathrm{eV}$ ). Because we were interested mainly in the structure of FMS region, the energy step increments varied between $2.0 \mathrm{eV}, 0.2 \mathrm{eV}$, and $2.0 \mathrm{eV}$ over the ranges $-22 \mathrm{eV}$ to $-2 \mathrm{eV},-2 \mathrm{eV}$ to $18 \mathrm{eV}$, and $18 \mathrm{eV}$ to $38 \mathrm{eV}$ above the iron absorption edge, respectively. The acquisition time for tissue samples was $30 \mathrm{~s}$ per energy step, while for standards $2 \mathrm{~s}$. The beam size for XANES analysis was about $16 \mu \mathrm{m} \times 14 \mu \mathrm{m}$.

The Mössbauer spectra of the same compounds were obtained from powdered samples at room temperature. The $\gamma$-ray source was ${ }^{57} \mathrm{Co}$ in rhodium matrix and the velocity scale was calibrated using iron foil (all isomer shifts are quoted relative to iron). Computer fitting of spectral data was undertaken using the MOSMOD program. Additionally, the Mössbauer spectra of $\left[\mathrm{Fe}(\mathrm{Hka})_{3}\right]$ and $\left[\mathrm{Fe}(\text { etmal })_{3}\right]$ were recorded at $77 \mathrm{~K}$.

\section{Results}

In case of high spin compounds, iron valence state may be easily distinguished from the Mössbauer isomer shift and energy shift of the absorption edge in XANES spectra, although in last case the interpretation may be influenced by local coordination of Fe [4]. However, some additional information on the subtle aspects of iron chemical bonding may be concluded from the intensity of the pre-peak in XANES spectra.

Local electronic states of $\mathrm{Fe}(\mathrm{III})$ in complexes with $\alpha$-cycloketoenoles, $\left[\mathrm{Fe}(\mathrm{Hka})_{3}\right](\mathrm{Hka}$ - kojic acid) (1) and [Fe(etmal) 3$]$ (etmal — ethylmaltol) (2) have been considered. The Mössbauer spectra of both compounds show the relaxation effects (Fig. 1) [5]. The relaxation time is temperature independent in case of $\left[\mathrm{Fe}(\mathrm{Hka})_{3}\right]$ which implies spin-spin character of the relaxation process, according to $S=5 / 2$ state of iron. In case of $\left[\mathrm{Fe}(\text { etmal })_{3}\right]$ the relaxation is temperature dependent, which is related to spin-lattice relaxation, which points out non-vanishing orbital moment, arising from some spd hybridization of iron orbitals. Indeed, the isomer shift of $\left[\mathrm{Fe}(\mathrm{Hka})_{3}\right]$ (IS $\left.=0.32 \mathrm{~mm} / \mathrm{s}\right)$ is higher than of $\left[\mathrm{Fe}(\text { etmal })_{3}\right]$ (IS = $0.17 \mathrm{~mm} / \mathrm{s}$ ), due to the $4 s$ contribution to the electron density in the last case.
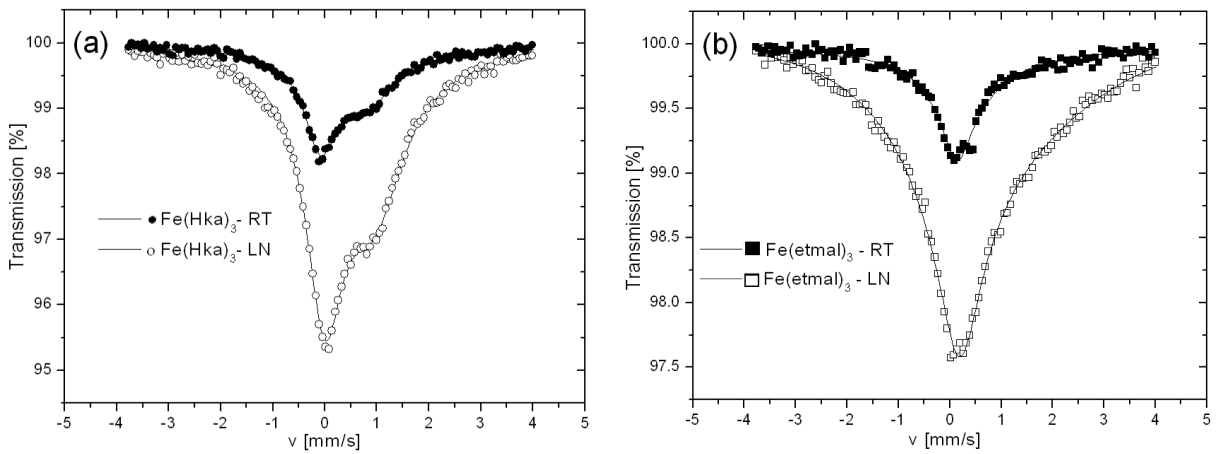

Fig. 1. Mössbauer spectra of (a) kojic acid and (b) ethylmalthol recorded in room and liquid nitrogen temperature, showing two types of relaxation processes. 

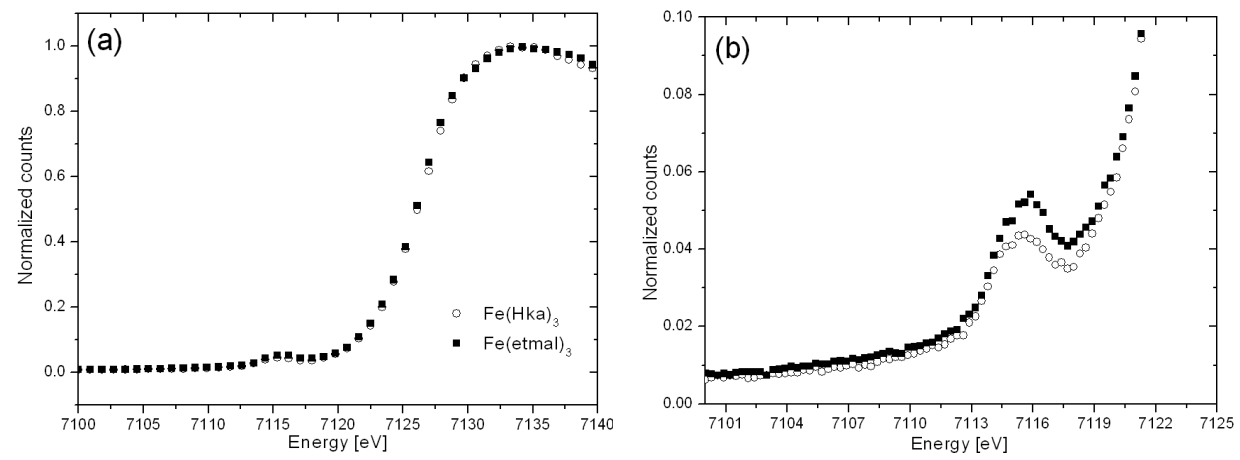

Fig. 2. (a) XANES spectra of kojic acid and ethylmaltol; (b) in the bigger scale a difference in pre-peak intensity is visible.

The only, but clear, difference in XANES spectra of these two compounds is the increase in the intensity of pre-peak in case of $\left[\mathrm{Fe}(\text { etmal })_{3}\right]$ (Fig. 2). We interpret this pre-peak as the $1 s \rightarrow 3 d$ (forbidden) transition; the enhanced probability of this transition due to admixture of $p$-states indeed explains the temperature dependent relaxation in this compound.

In case of low spin compounds, due to the covalence effects, the concept of valence (or charge state) partly fails, the $\mathrm{Fe}^{2+}$ and $\mathrm{Fe}^{3+}$ states are related rather to the spin states, $S=1 / 2$ and $S=0$, respectively. The Mössbauer hyperfine parameters, i.e. isomer shift and quadrupole splitting, are characteristic of these both states. On the contrary, the energy of the absorption edge does not change for $\mathrm{Fe}^{2+}$ and $\mathrm{Fe}^{3+}$, although FMS region shows some fine structure arising from partly occupied (or empty) molecular orbital with some $p$-character. The question whether that fine structure carries information on spin state of iron is still open.

XANES investigations of the Fe $K$-edge absorption edge in cancerous tissues show that its position and shape is like for $\mathrm{Fe}^{3+}$ high spin in $\mathrm{Fe}_{2} \mathrm{O}_{3}$, exhibiting

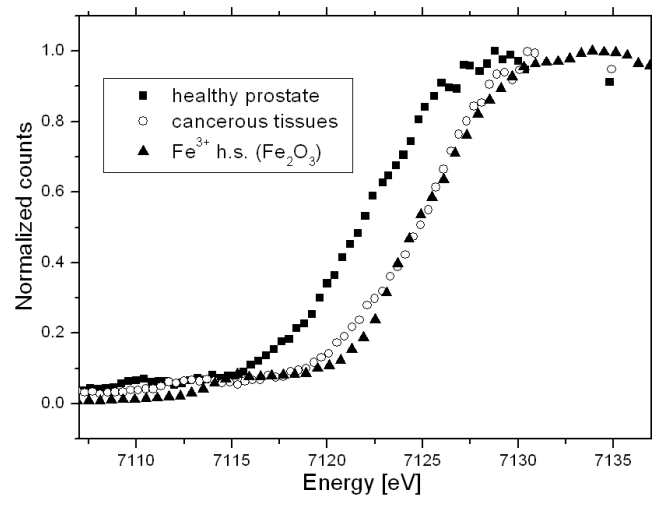

Fig. 3. Iron XANES spectra from places containing high iron concentration in the cancerous and healthy prostate tissues, compared with standard $\left(\mathrm{Fe}_{2} \mathrm{O}_{3}\right)$. 
visible energy shift of the FMS in comparison with healthy tissue (Fig. 3). This may suggest that formation of $\mathrm{Fe}^{3+}$ high spin state of iron is somehow related to the pathogenesis of cancer. The valence state of $\mathrm{Fe}$ in healthy tissue $\left(\mathrm{Fe}^{3+}\right.$ low spin or $\mathrm{Fe}^{2+}$ ) could not be determined.

\section{Concluding remarks}

The proposed scenario of investigation of iron electronic states in tissue is as follows. Step (1) - recording the Mössbauer and XANES spectra of standard (model) biological samples. This will allow relating the Fe valence or spin states with XANES spectra in this class of materials. Step (2) - recording of iron XANES spectra of tissues. The comparison of such spectra with result obtained for model samples may allow the determination of valence and spin states of iron in normal and neoplasmatic cells.

The comparison of XANES and Mössbauer spectra of the same samples may give hints for better interpretation of measured parameters [6] (fine structure of the absorption edge, energy and intensity of pre-peak, isomer shift, quadrupole splitting, relaxation processes, etc.) in terms of subtle aspects of chemical bounds.

\section{Acknowledgments}

The authors wish to thank Prof. Jerzy Stachura from Collegium Medicum at the Jagiellonian University for his assistance in tissue samples classification. The XANES measurements were supported by HASYLAB, DESY, Hamburg, Germany under project II-02-010. This work was supported by the IHP-Contract HPRI-CT1999-00040/2001-00140 of the European Commission and the State Committee for Scientific Research (Poland) grant No. 4 T08C 00124.

\section{References}

[1] D. Galaris, A. Evangelou, Crit. Rev. Oncol./Hematol. 42, 93 (2002).

[2] W.M. Kwiatek, A. Banaś, K. Banaś, M. Gajda, M. Gałka, G. Falkenberg, T. Cichocki, J. Alloys Comp. 401, 178 (2005).

[3] A. Mottana, EMU Notes in Mineralogy 6, Chapter 12 (2004).

[4] A. Pattek-Janczyk, K. Zaremba, J. Stanek, A. Adamski, Ann. Pol. Chem. Soc. 3, 280 (2005).

[5] A.J. Berry, H.St.C. O’Neill, K.D. Jayasuriya, S.J. Campbell, G.J. Foran, Am. Mineralog. 88, 967 (2003).

[6] G.A. Waychunas, M.J. Apted, G.E. Jr. Brown, Phys. Chem. Minerals 10, 1 (1983). 